\title{
Investigating the effect of outer layer of magnetic particles on cervical cancer cells HeLa by magnetic fluid hyperthermia
}

\author{
Anand Bhardwaj ${ }^{1,2}$, Neeraj Jain ${ }^{2 *}$ and Kinnari Parekh ${ }^{1 *}$ (D)
}

\author{
*Correspondence: \\ neerajjain.as@charusat.ac.in; \\ kinnariparekh.rnd@charusat. \\ ac.in \\ ${ }^{1}$ Dr. K C Patel R \& D \\ Centre, Charotar University \\ of Science \& Technology, \\ CHARUSAT Campus, Changa, \\ 388421 Anand, India \\ ${ }^{2}$ P D Patel Institute \\ of Applied Sciences, Charotar \\ University of Science \& \\ Technology (CHARUSAT), \\ Changa, 388421 Anand, \\ India
}

\begin{abstract}
Background: Magnetic fluid hyperthermia (MFH) is a successful nanotechnology application in recent decade where a biocompatible magnetic fluid is used to kill cancer cells in a controlled heating using AC magnetic field. In the present study, two ferrite-based magnetic fluids, with and without surfactant coating, were synthesized to study the effect of the outer layer of magnetic nanoparticles on cervical cancer cells. The magnetic fluid without surfactant coating (MFWI) was made stable by providing negative charge on the surface of each particle. On the other hand, lauric acid was used as a surfactant to have a stable dispersion of particles in aqueous media (MFWL).
\end{abstract}

Methods: The structural, magnetic properties and induction heating response of both the fluids were investigated using XRD, VSM, DLS, TGA, FTIR, and a high-frequency induction heater. The in vitro cytotoxicity of the synthesized fluids was observed on HeLa cells by performing MTT assay, and the effect of magnetic fluid hyperthermia was examined using Trypan blue assay.

Results: The crystallite size of surfactant stabilized particles was higher $(11.0 \pm 0.5 \mathrm{~nm})$ compared to the charge stabilized particles $(8.3 \pm 0.5 \mathrm{~nm})$. Induction heating experiments showed that the specific absorption rate of the surfactant-coated particles was almost double compared to ionic particle fluid. Magnetic fluid hyperthermia up to 1 hour at a concentration of $0.25 \mathrm{mg} / \mathrm{mL}$ of surfactant-coated magnetic fluid and $0.2 \mathrm{mg} / \mathrm{mL}$ concentration of charged fluid resulted in approximately 66 and $80 \%$ cell death, respectively, compared to untreated control cells.

Conclusion: The preliminary analysis of this study shows significant cell death due to hyperthermia, wherein MFWI revealed higher cytotoxicity compared to MFWL. Additional analysis into the role of the outer stabilizing layer on nanoparticle's surface, concentration of nanoparticles, and hyperthermic duration is desirable to utilize MFH as a futuristic anti-cancer therapeutic tool.

Keywords: Magnetic fluid, Surfactant coating, Specific absorption rate, Cytotoxicity, Magnetic fluid hyperthermia included in the article's Creative Commons licence and your intended use is not permitted by statutory regulation or exceeds the permitted use, you will need to obtain permission directly from the copyright holder. To view a copy of this licence, visit http://creativecommons.org/ licenses/by/4.0/. The Creative Commons Public Domain Dedication waiver (http://creativecommons.org/publicdomain/zero/1.0/) applies to the data made available in this article, unless otherwise stated in a credit line to the data. 


\section{Background}

Magnetic fluids are stable colloidal dispersion of magnetic nanoparticles (MNPs) in a suitable carrier liquid having wide applications including spacecraft propulsion, heat transfer, magnetic damping, targeted drug delivery, diagnosis and therapeutic, etc. (Su et al. 2016) For stable dispersion, these fluids generally include surfactant coating on MNPs. Magnetic fluid hyperthermia (MFH) has been proposed as a potent medical application of magnetic fluid for the treatment of different cancers (Das et al. 2019). In this type of cancer treatment strategy, the temperature of cancer cells is increased up to $43-45{ }^{\circ} \mathrm{C}$, the hyperthermia (HT) temperature window, using induction heating of magnetic fluid under high-frequency alternating magnetic field that leads to the killing of cancerous cells (Chang et al. 2018). This generated heat is quantified by a parameter, called Specific Absorption Rate (SAR) (Rosensweig 2002). The iron oxide nanoparticles, especially magnetite and maghemite, are mostly used for this biomedical application due to biocompatibility and the greater hyperthermic heating response (Patil et al. 2015; Laffon et al. 2018).

For therapeutic applications, stable magnetic fluids are needed; however, the stability of the colloidal magnetic fluid in water as well as in cell culture medium is challenged due to the presence of proteins, especially when the concentration of magnetic particles is very low (Soares et al. 2014; Hondow et al. 2012). Various methods have been reported to achieve the stable magnetic fluid, such as coating with a long chain organic/carbon surfactant or by providing the electric charge on the surface of MNPs, to make them electrostatic repulsive (Giri et al. 2008; Filippousi et al. 2014; Wu et al. 2008; Tourinho et al. 1990). Although these surfactant or charge coatings provide stability to the colloidal system, sometimes this produces additional cytotoxicity to the cells and hence creates issues regarding the biocompatibility of fluid (Zavisova et al. 2019). Therefore, there is a need to study the effect of these coatings on MNPs for their effective use in medical therapeutic approaches such as MFH.

Bare MNPs having a very small size possess large surface energy; as a result, they are very unstable and reactive. In order to minimize their surface energy, these uncoated particles tend to aggregate. Some kind of repulsive energy needs to be created to prevent their aggregation so that when these particles come closer, the repulsive energy keeps them apart. One way to create the repulsion among the particles during its close approximation is to coat the surface using various surface-active agents (also known as surfactant). For example, short-chain hydrocarbon such as oleic acid, polymeric molecules like polyethylene glycol (PEG), polyvinyl alcohol (PVA), and inorganic materials like silica have been suggested to prevent or to decrease the aggregation of MNPs, thereby increasing the stability and biocompatibility (Wu et al. 2008). Various other polymeric molecules such as polyvinyl pyrrolidine (PVP), polyacrylic acid, polystyrene, polymethyl methacrylate, polydipyrrole/dicarbazole, etc. and natural dispersants like ethyl cellulose, dextran, citric acid, casein, chitosan, starch, gelatin, etc. have also been utilized for coating the MNPs to increase their stability (Xu et al. 2014). These coatings can also be conjugated with various ligands, proteins, drugs, enzymes, antibodies, fluorophores or nucleotides, etc., for subsequent applications for imaging technique, therapeutic technique, or targeted drug delivery (Maxwell et al. 2008). The coating should, however, not affect the superparamagnetic behavior of the MNPs. 
The present study aimed to investigate the cytotoxicity of magnetic fluid, stabilized using two different approaches: (i) sterically stabilized fluid and (ii) ionic stabilized fluid, on HeLa cells. The first one uses the surfactant, which overcomes the short-range van der Waals and long-range magnetic dipolar attractive forces by steric repulsion due to the hydrophobic chain length of the surfactant. In contrast, the latter approach uses Coulomb repulsion force to overcome these attractive forces which is created by grafting anions/cations on the surface of each nanoparticle. In order to ensure the stability of both types of fluids in the aqueous environment, even at extensive dilution, we used two standard methods of synthesis for making dilution-insensitive water-based magnetic fluid. In the first case, lauric acid was used to get the stable magnetic fluid (Khalafalla et al. 1980), whereas in the later case, Massart's method of preparing ionic magnetic fluid using $\mathrm{Fe}\left(\mathrm{NO}_{3}\right)_{3}$ treatment was adopted (Massart 1981). These magnetic fluids (MFs) have been prepared and used extensively by many researchers for various purposes, yet the detailed influence of the effect of the outer layer on in vitro MFH has not been reported (Giri et al. 2008; Filippousi et al. 2014; Wu et al. 2008; Tourinho et al. 1990).

The fluid prepared by the first method was labeled as MFWL, which was coated with organic surfactant lauric acid, and the second one was made colloidally stable by providing the charge on the surface of MNPs by $\mathrm{NO}_{3}^{-}$and was labeled as MFWI. These fluids were studied for their structural, magnetic, and induction heating properties. Also, the cytotoxicity and hyperthermic effect of these MFs were analyzed on the cervical cancer cell line HeLa using MTT and TPB assays. The hyperthermia study on HeLa cells was performed at a magnetic field of $15.3 \mathrm{kA} / \mathrm{m}$ and frequency $330 \mathrm{kHz}$ within the upper safety limit of this product $(\mathrm{H} \times \mathrm{f})$ as $5 \times 10^{9} \mathrm{~A} / \mathrm{m}$ (Obaidat et al. 2015). Both the fluids exhibited colloidal stability and cytotoxicity with and without hyperthermia.

The novelty of this work was to prepare the dilution-insensitive magnetic fluid using surfactant-stabilized and charge-stabilized magnetic particles and study its in vitro effect on HeLa cells. To the best of our knowledge, with the charge stabilized fluid, such a study has not been reported in the literature on HeLa cells or any other cell types. Moreover, the effect of induction heating time using such fluid on the survival of HeLa cells is an important experiment to decide the suitability of this strategy for the treatment of cervical cancer using magnetic fluid hyperthermia. In our earlier study (Bhardwaj et al. 2020), the fluid used was sensitive to the temperature that would automatically fix the temperature rise, whereas in this case, particles are not sensitive to temperature, so the combination of particle concentration, its stability against dilution, and magnetic field were the deciding factors to stabilize the $45^{\circ} \mathrm{C}$ temperature. In this particular case, if the fluid shows concentration-dependent SAR then it cannot be considered for the treatment. The key idea was to maintain the hyperthermia temperature of $43-45^{\circ} \mathrm{C}$ for a longer duration using these fluids within the safety limit of field and frequency. These results will be helpful in planning in vivo animal experiments strategies.

\section{Materials and methods} Synthesis of magnetic fluid

Two different magnetic fluids were synthesized using the chemical co-precipitation route. $1 \mathrm{M} \mathrm{FeCl}_{2} \cdot 4 \mathrm{H}_{2} \mathrm{O}$ and $1 \mathrm{M} \mathrm{FeCl}_{3} \cdot 6 \mathrm{H}_{2} \mathrm{O}$ were taken in the stoichiometry of 
$\mathrm{Fe}^{2+}: \mathrm{Fe}^{3+}$ as $1: 2$, mixed together in a beaker, and designated as salt solution. The salt solution was added to $8 \mathrm{M} \mathrm{NH}_{4} \mathrm{OH}$ under vigorous stirring. The $\mathrm{pH}$ of the solution was maintained at 9.5 for 10 min to form the black precipitates of $\mathrm{Fe}_{3} \mathrm{O}_{4}$ nanoparticles. These particles were then washed with de-mineralized water to remove the impurity. Afterward, lauric acid was added, and the mixture was heated to $90^{\circ} \mathrm{C}$ for $5 \mathrm{~min}$ (Parekh and Upadhyay 2017). The fluid was labeled as MFWL. To prepare ionic magnetic fluid, the freshly prepared $\mathrm{Fe}_{3} \mathrm{O}_{4}$ nanoparticles using the above-mentioned procedure after washing were peptized using an appropriate particle surface treatment, which brings electric charges onto the surface. These electric charges provided by adsorbed $\mathrm{H}_{3} \mathrm{O}^{+}$ions introduce repulsive force between the particles (Massart 1981). The fluid thus prepared was labeled as MFWI.

\section{Characterization of magnetic fluids}

$\mathrm{X}$-ray diffraction pattern of the samples was obtained using powder X-ray diffractometer model D2 phaser (Bruker, Germany) having Copper $K_{\alpha}$ source producing a wavelength of $0.154056 \mathrm{~nm}$ and heating filament operating at $30 \mathrm{kV}$ and $10 \mathrm{~mA}$. Dried particles were ground and passed through a 400 mesh before placing them on the sample holder. The angular range $2 \theta$ was varied from $25^{\circ}$ to $70^{\circ}$ in step size of $0.05^{\circ}$. The magnetic properties of the fluid samples were measured using a vibrating sample magnetometer (VSM) model 7404 from Lakeshore, USA, at $25{ }^{\circ} \mathrm{C}$ temperature by varying the magnetic field from 0 to $1 \mathrm{~T}$. JEOL, JEM 2100 operated at $200 \mathrm{kV}$ was used to capture Transmission Electron Miscroscoy (TEM) images. The sample for TEM image was prepared by diluting the fluid in an aqueous medium followed by ultra-sonication, and a drop of fluid was placed on a carbon-coated copper grid. The grid with the sample was dried overnight under vacuum.

To study the binding of surfactant on the particle surface, thermo-gravimetric analyzer (TGA) model TGA-DSC-1 from METTLER, Switzerland, was used. Under an inert gas environment, the temperature was varied in steps of $10{ }^{\circ} \mathrm{C}$ per minute between 25 and $500{ }^{\circ} \mathrm{C}$. To confirm the binding of surfactant with particle surface, Fourier transform infrared spectrometer (FTIR) model Nicolet from Thermo Scientific, USA, was used. The pellet made from the dried coated particles mixed with $\mathrm{KBr}$ was placed in the instrument while varying the wave number from 400 to $4000 \mathrm{~cm}^{-1}$. DLS measurement was performed using particle size analyzer model S90 from Malvern Instruments Ltd., UK, for identifying the hydrodynamic size. For this purpose, the dilutions were made in Milli-Q water, and the measurement was performed at $298 \mathrm{~K}$ while considering the refractive index of MNPs as 1.52 and dispersant as 1.33 .

Hyperthermia measurements were recorded using the induction heating system, Easy Heat 8310 (Ambrell, USA). For this, $1 \mathrm{~mL}$ of magnetic fluid (with respective dilution in water) was filled in a 2-mL capacity plastic vial enclosed in a thermally insulated rubberized cork. The vial was placed at the radial as well as vertical center of $2 \times 2$ turns Helmholtz coil having an inner diameter of $60 \mathrm{~mm}$. The hollow copper coil was connected to the heat station and power supply. To prevent heating of the coil, water was circulated through the coil via a water circulating chiller so as to keep the coil temperature below $30{ }^{\circ} \mathrm{C}$. The change in temperature of the sample due to the applied AC magnetic field was measured using an optical fiber thermocouple whose tip was inserted in the vial 
such that the tip always remained at the center of the coil as well as in the middle of the volume occupied by the magnetic fluid. The optical fiber thermocouple was connected to the computer, and the temperature was measured with an accuracy of $\pm 0.01{ }^{\circ} \mathrm{C}$. The magnetic fluid with respective dilution in water was ultrasonicated for $30 \mathrm{~s}$ before starting the experiment so as to ensure the uniform distribution of particles. The hyperthermia experiments were repeated three times for every sample to ensure the accuracy of the results.

The magnetic field was varied from 1.7 to $10 \mathrm{kA} / \mathrm{m}$ by changing the current through the controls given on power supply, and concentration $(10-1 \mathrm{mg} / \mathrm{mL})$ was varied by making respective dilutions in deionized water. The same $2 \times 2$ turns Helmholtz coil was used for in vitro cell culture experiments with induction heating. The frequency was kept fixed at $330 \mathrm{kHz}$ during all MFH experiments.

\section{Cell line culture}

For in vitro experiments, cervical cancer cell line HeLa was procured from National Centre for Cell Science, Pune, India, and cultured in our biosafety level II laboratory. For the culture purpose, T25 vented culture flasks (Corning, USA) were used. The complete media was prepared by supplementing Eagle's minimal essential medium (EMEM, Gibco-Thermofisher, USA), with 10\% heat-inactivated fetal bovine serum (Gibco-Thermofisher, USA), $100 \mathrm{U} / \mathrm{mL}$ Penicillin, $100 \mu \mathrm{g} / \mathrm{mL}$ Streptomycin, and $0.25 \mu \mathrm{g} / \mathrm{mL}$ Amphotericin B (Gibco-Thermofisher, USA). The cells were grown in a $37{ }^{\circ} \mathrm{C}$ incubator with $5 \%$ $\mathrm{CO}_{2}$ and $95 \%$ relative humidity.

\section{Cell viability assays}

MTT [3-(4, 5-dimethylthiazol-2-yl)-2, 5-diphenyltetrazolium bromide] cell viability assay (Mosmann 1983) was performed on HeLa cells to determine $50 \%$ inhibitory concentration, $\mathrm{IC}_{50}$. Briefly, in a 96-well tissue culture plate, $10^{4}$ cells/well were seeded in triplicates and grown for $24 \mathrm{~h}$, followed by treatment with magnetic fluid diluted in cell culture media with concentration range varying from 0.3 to $0.03 \mathrm{mg} / \mathrm{mL}$. A set of three wells without MNPs served as untreated controls.

After incubating with magnetic fluid for $24 \mathrm{~h}$, media containing MF was removed, and the cells were washed with phosphate-buffered saline (PBS) to remove the suspended/ free MNPs from the wells. Thereafter, $300 \mu \mathrm{l}$ of media and $25 \mu \mathrm{l}$ of MTT solution $(5 \mathrm{mg} /$ $\mathrm{mL}$ in PBS) was added to each well, followed by $3 \mathrm{~h}$ of incubation. Afterward, media from each cell was removed, and $100 \mu \mathrm{L}$ dimethyl sulfoxide per well was added to dissolve the formed crystal formazan. The absorbance was measured at $570 \mathrm{~nm}$ on an ELISA plate reader (Molecular Devices, USA). The cell viability was calculated using Eq. 1:

$$
\text { Cellviability } \%=\frac{\begin{array}{c}
\text { averageabsorbancefromtreatedcells } \\
\text { afterMFtreatmentintriplicates }
\end{array}}{\text { averageabsorbancefromcontrolcellsintriplicates }} \times 100
$$

For trypan blue (TPB) assay (Strober 2001), HeLa cells were cultured on $35 \mathrm{~mm}^{2}$ culture dishes (CDs) (Corning, USA) with a seeding density of $2.5 \times 10^{5}$ cells/CD and kept in incubator till 70-80\% confluency. Subsequently, magnetic fluid was added, and magnetic fluid hyperthermia was performed. Afterward, the cells were PBS washed, followed 
by trypsinization using $0.25 \%$ Trypsin-EDTA (Gibco-Thermofisher, USA). The detached cells were stained with trypan blue solution, and viability was counted using a hemocytometer. The viability of cells was estimated using the Eq. 2 :

$$
\text { Cellviability\% }=\frac{\text { averagecountoflivecellsintriplicates }}{\text { averagecountoflive }+ \text { deadcellsintriplicates }} \times 100
$$

\section{Hyperthermia experiments on cancer cells}

HeLa cells grown on CDs were treated with the near $\mathrm{IC}_{50}$ values of 0.25 and $0.2 \mathrm{mg} / \mathrm{mL}$ of MFWL and MFWI, respectively, for $24 \mathrm{~h}$. Thereafter, the CDs were placed within the $2 \times 2$ turns heating coil in a wooden Class II/ A2 biosafety cabinet to avoid contamination during the experiments. All experiments were performed under constant temperature and pressure maintained in the biosafety level II laboratory of our institute. Briefly, the method involved seeding 0.25 million cells in six culture dishes numbered as (1) control cells without MF and without hyperthermia, HT; (2) cells without MF, with $30 \mathrm{~min}$ HT; (3) cells without MF, with 60 min HT; (4) cells with MF, without HT (5) cells with MF, with 30 min HT; and (6) cells MF, with 60 min HT. Once the desired confluency of 70-80\% was reached, MF was added to respective CDs, and cells were further allowed to grow for the next $24 \mathrm{~h}$. CDs 2, 3, 5, and 6 underwent induction heating. The magnetic field of $15.3 \mathrm{kA} / \mathrm{m}$ was set to achieve the hyperthermic window of $43-45^{\circ} \mathrm{C}$, which was maintained throughout the treatment period. The tip of the fiber optic sensor was every time wiped with 70\% ethanol before dipping in the CDs. After hyperthermia, the CDs underwent TPB assay to assess their viability. Figure 1 represents a flowchart of the steps involved in the hyperthermia experiment. The results of each set were normalized against the untreated cells of CD1.

\section{Statistical analysis}

All the in vitro experiments were performed in triplicate. The data are presented as mean values \pm standard error after obtaining mean and standard deviations. Students' $t$ test was performed to calculate the levels of significance, and the results were considered significant if the $p$-value was less than 0.05 .

\section{Result and discussion}

Figure 2a shows the X-ray diffraction pattern of dried MNPs used for MFWL and MFWI fluid preparation. The similarity between patterns indicates that stability procedures did not change the crystal structure of MNPs. The crystal structure obtained from the pattern analysis indicates impurity-free single-phase cubic spinel ferrite with no extra peaks other than the ferrite phase. For calculating the crystallite size $\left(D_{\text {XRD }}\right)$, the most intense peak (311) and Scherrer formula (Eq. 3) was used (Patterson 1939):

$$
D_{\mathrm{XRD}}=\frac{0.9 \lambda}{B \cos \theta},
$$




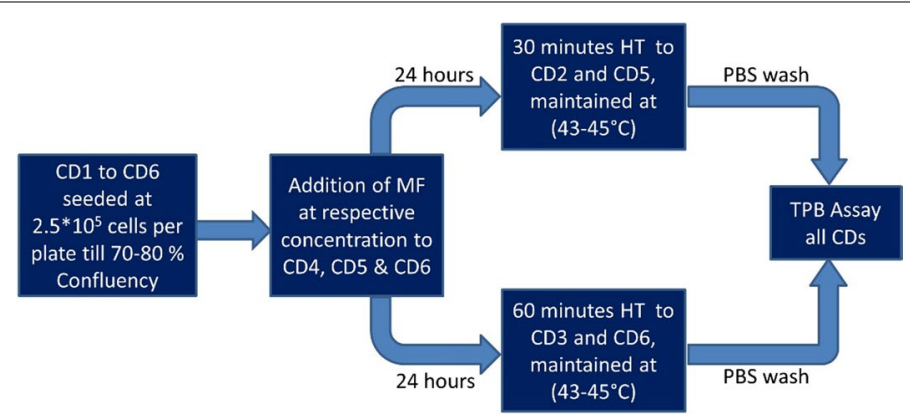

Fig. 1 Flowchart of hyperthermia experiments performed on HeLa cells
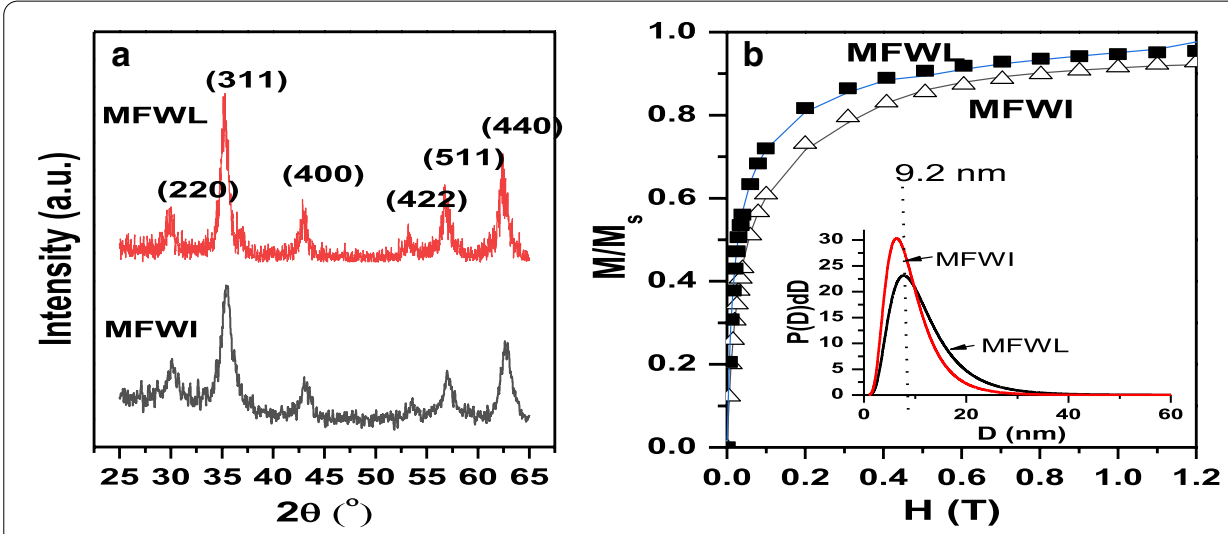

Fig. 2 a X-ray diffraction pattern of dry particles and $\mathbf{b}$ magnetic measurement curves of fluid for both the samples. Inset $\mathbf{b}$ shows the size distribution curve for both the fluids

where $B$ denotes full-width half maxima of diffraction peak, $\lambda$ is X-ray wavelength, and $\theta$ is the Bragg's angle. The crystallite size of surfactant-stabilized particles (MFWL) was found to be higher $(11.0 \pm 0.5 \mathrm{~nm})$ as compared to charge stabilized particles $(8.3 \pm 0.5 \mathrm{~nm})$. The procedure of charge grafting might have removed some of the $\mathrm{Fe}$ ions from its surface, but that affects physical size only. The slight variation in observed particle size may be due to the probability of size variation from batch to batch, which is common for chemical process, especially when $\mathrm{NH}_{4} \mathrm{OH}$ is used as a base ion for the precipitation. This was also confirmed by calculating the lattice parameter 'a' using the analytical method (Suryanarayana and Norton 1998). The lattice parameter was found to be $0.8436 \pm 0.0005 \mathrm{~nm}$ for MFWL particles and $0.8360 \pm 0.0005 \mathrm{~nm}$ for MFWI particles. X-ray diffraction peak positions for both MNPs were indexed as (220), (311), (400), (422), (511), and (440).

Magnetic response as a function of magnetic field for both fluids is shown in Fig. 2b. The magnetic characterization experiments were performed at room temperature $\left(25{ }^{\circ} \mathrm{C}\right)$. The obtained data were fitted with Langevin function (Parekh et al. 2008) for superparamagnetic non-interacting particles to obtain the magnetic parameters like the magnetic size of particles $\left(D_{\mathrm{m}}\right)$, size distribution $(\sigma)$, domain magnetization $\left(M_{\mathrm{d}}\right)$, and saturation magnetization $\left(M_{\mathrm{s}}\right)$. Domain magnetization of both fluids was kept the same as $450 \mathrm{kA} / \mathrm{m}$. $D_{\mathrm{m}}$ was found to be $10.3 \mathrm{~nm}$ for MFWL and $8.2 \mathrm{~nm}$ for MFWI. The 
magnetic size is important to know because the reduced magnetic size can lower the heating response during the induction heating. The magnetic size distribution $\sigma$ was found as 0.53 and 0.50 , respectively, for MFWL and MFWI fluid. The obtained saturation magnetization was much lower for MFWI (15 Gauss) as compared to 145 Gauss for MFWL. This difference in magnetization can be attributed to a lower concentration of MFWI $(11.6 \mathrm{mg} / \mathrm{mL})$ as compared to MFWL $(217 \mathrm{mg} / \mathrm{mL})$. The inset Fig. $2 b$ shows the size distribution curve for both the fluids. The dotted line shows the critical diameter of $9.2 \mathrm{~nm}$ above which the particles are dominated by the Brownian mechanism (Rosensweig 2002). It is seen that almost $60 \%$ particles in MFWL sample is above this critical diameter, whereas for MFWI sample it is $42 \%$.

Figure 3a and $\mathrm{c}$ shows the TEM image of the sample MFWL and MFWI, respectively. The particle morphology, as seen from both the images, is spherical in shape. In addition, these particles are well separated from each other. The size of these particles was estimated using ImageJ software. Nearly 300 particles from various TEM images were considered for plotting the histogram which is shown in Fig. 3b and d, respectively, for MFWL and MFWI samples. The histogram is fitted with the log-normal distribution curve (red line) that fits with the mean size of $10.2 \pm 0.24 \mathrm{~nm}$ with a size distribution of 0.18 for the MFWL sample and 7.6 $\pm 0.04 \mathrm{~nm}$ with a size distribution of 0.14 for the MFWI sample. The size distribution in MFWI is narrow as compared to that of MFWL. Also, the TEM size is observed less for MFWI as compared to MFWL, which matches with the results obtained from the XRD measurement.

In the thermogravimetric experiment, the particles showed a total weight loss of $32.8 \%$ for surfactant-coated particles (MFWL) and 16\% for charge grafted particles (MFWI) as shown in Fig. 4a and b. The first weight loss of approximately $2 \%$ occurring below $100{ }^{\circ} \mathrm{C}$ in both particles is due to the evaporation of physi-adsorbed water molecules attached to the particle surface. The major weight loss in the case of MFWL happening at a high temperature indicates the chemical attachment of surfactant on the particle surface, and the two-step loss indicates the bilayer arrangement of surfactant (Pradhan et al. 2007a; Mahdavi et al. 2013). The particles of MFWL showed major weight loss occurring in two steps, at $248^{\circ} \mathrm{C}$ and $344^{\circ} \mathrm{C}$, while, for MFWI major weight loss occured in three steps at $209^{\circ} \mathrm{C}, 287^{\circ} \mathrm{C}$, and $357^{\circ} \mathrm{C}$. In the case of MFWL sample, The first weight loss of $20.2 \%$ was due to the removal of secondary layer or extra surfactant, whereas the second loss of $28.7 \%$ was due to the removal of the chemically adsorbed primary layer of surfactant. In the case of MFWI, the removal of adsorbed double diffuse layers (Cao and Wang 2011) of ions from the particle surface resulted in the multiple transitions between 209 and $357{ }^{\circ} \mathrm{C}$. After $400{ }^{\circ} \mathrm{C}$ the transition becomes stable, indicating no phase change above this temperature.

Figure 4c shows the FTIR spectra of surfactant lauric acid, the lauric acid-coated MNPs, and charge grafted MNPs. The peak observed at $1698 \mathrm{~cm}^{-1}$ in the case of lauric acid spectrum shifted to $1704 \mathrm{~cm}^{-1}$ for MFWL, indicating the $\mathrm{C}=\mathrm{O}$ stretch of the carboxylic head of the surfactant molecule and its covalent bonding to the particle surface. The characteristic iron oxide Fe-O stretching vibration occurs at $567 \mathrm{~cm}^{-1}$ for MFWL and at $563 \mathrm{~cm}^{-1}$ for MFWI (Pradhan et al. 2007a). The band at $940 \mathrm{~cm}^{-1}$ corresponding to $\mathrm{O}-\mathrm{H}$ bending vibration in the spectra of lauric acid vanished in the spectra of MFWL, and the presence of a weak band at $1704 \mathrm{~cm}^{-1}$ indicated strong adsorption and close 

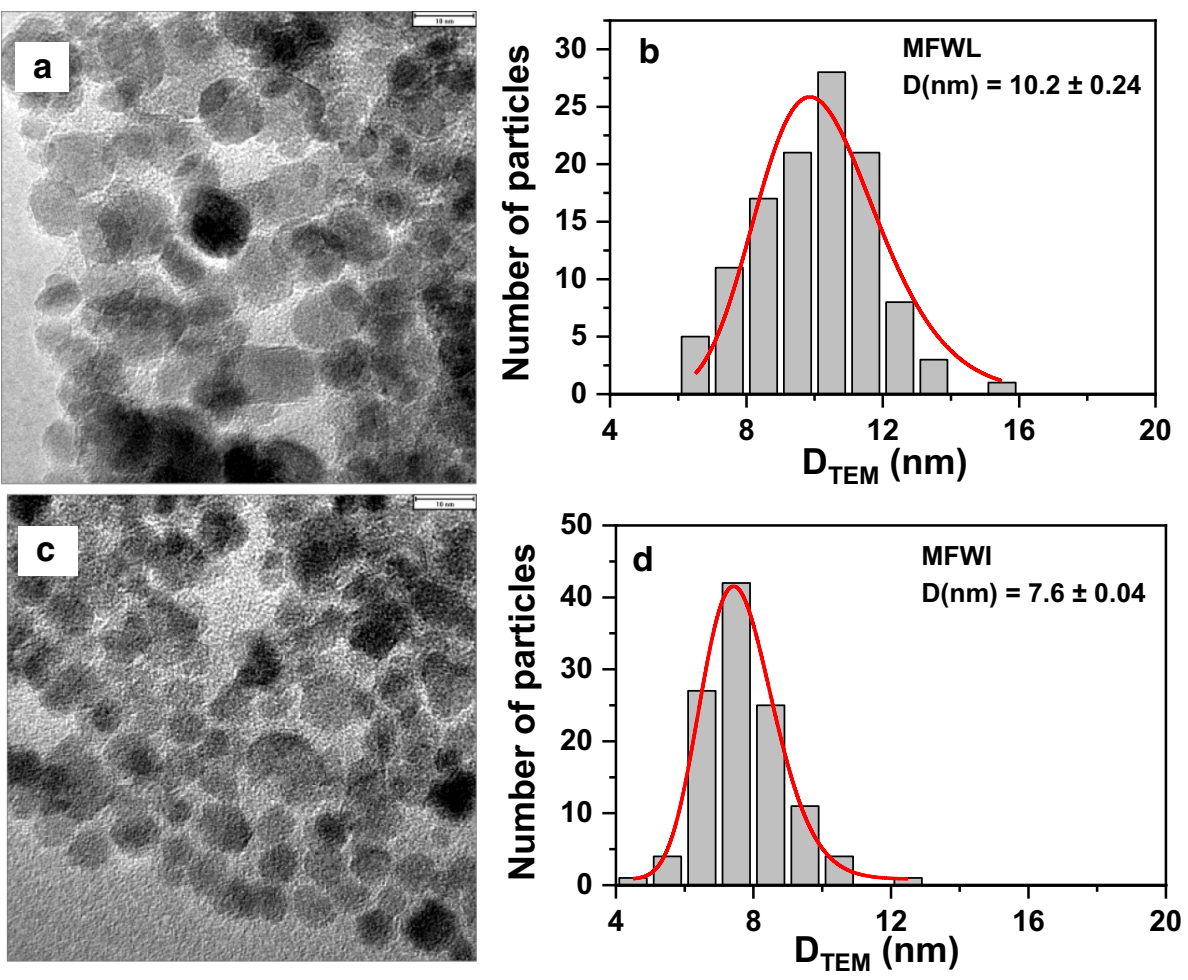

Fig. 3 TEM image (a and $\mathbf{c}$ ) and particle size distribution curve (b and $\mathbf{d}$ ) obtained from TEM images for MFWL and MFWI samples
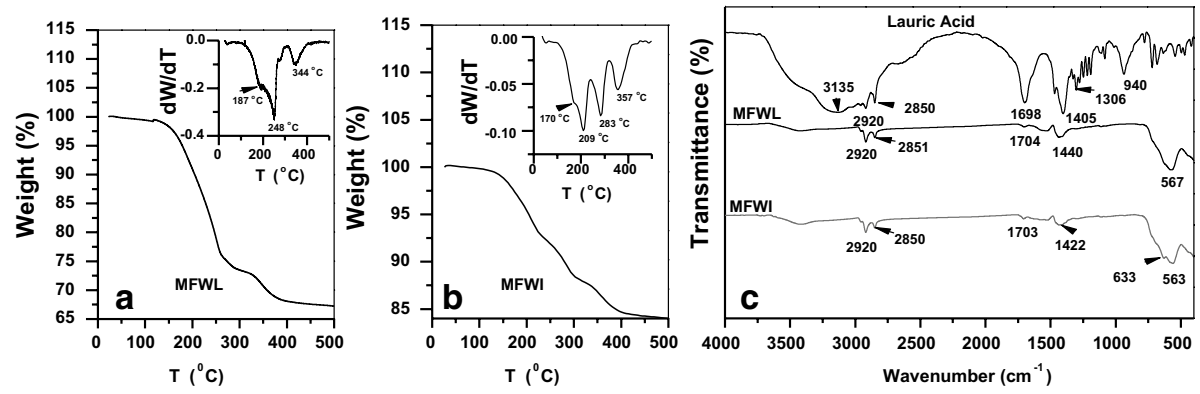

Fig. 4 Residual weight versus temperature for $\mathbf{a}$ MFWL and $\mathbf{b}$ MFWI. Inset figure for $\mathbf{a}$ and $\mathbf{b}$ shows the first-order derivative of weight loss as a function of temperature. (c) FTIR measurement of pure surfactant and MFWL and MFWI particles

packing of surfactant layers on particles (Lenin and Joy 2016). The band at $1422 \mathrm{~cm}^{-1}$ confirmed the presence of nitro group in the spectra of MFWI.

Figure $5 \mathrm{a}$ and $\mathrm{b}$ shows the log-normal distribution fit to the number distribution of both aqueous magnetic fluids. The hydrodynamic size measured was $29.3 \pm 0.3$ and $24.6 \pm 0.3 \mathrm{~nm}$ for MFWL and MFWI, respectively. The standard deviation of the distribution curve $(\sigma)$ was found to be 0.24 and 0.18 , respectively, for MFWL and MFWI. Hydrodynamic size is not the actual particle size as it contains the thickness of multiple layers of surfactant as well as diffuse layer of solution (water in our case) around the particle. Basically, DLS derives the hydrodynamic size of the particles using the concept 
of diffusion of the particles in the medium. The results show a higher value of hydrodynamic diameter $\left(D_{\mathrm{h}}\right)$ in both fluids as compared to the crystallite size obtained from the $\mathrm{X}$-ray diffraction pattern indicating the possibility of multiple layers of surfactant coating. This larger size can also be due to the formation of small aggregates stable in solution even after dilution (Odenbach 2002).

\section{Hyperthermia without cells}

The heat released due to magnetic fluids placed under the AC magnetic field is given by Eq. 4 defined as

$$
P_{\text {adsorbed }}=\mu_{0} \pi \cdot \chi^{\prime \prime} \cdot f \cdot H^{2},
$$

where $\mu_{0}$ is the permeability of free space, $\chi^{\prime \prime}$ is the imaginary component of susceptibility, $f$ is a frequency, and $H$ is the applied field strength (Rosensweig 2002). This heat dissipation is caused mainly by the relaxation of magnetic moments termed as Neel relaxation and Brownian relaxation. In Neel relaxation, there are rapid changes in the particle's magnetic moment due to opposition by the particle's crystalline structure, resulting in heat generation when exposed to the AC magnetic field. In Brownian relaxation, the heat is generated from the physical rotation of particles within the medium when particles attempt to realign themselves with the changing magnetic field. These relaxations also depend upon the size of magnetic particles (Odenbach 2002). The heating efficiency is quantified by the parameter SAR, which is equal to the dissipated power divided by the magnetic material density, showing that the SAR varies linearly with the product of frequency, $f$, and the square of the magnetic field $\left(H^{2}\right)$. From the induction heating data of the rise in temperature with respect to time, the SAR value was calculated using Eq. 5:

$$
\mathrm{SAR}=C_{p} \cdot \frac{\Delta T}{\Delta t} \cdot \frac{1}{\varphi_{\text {magnetic }}}
$$

where $C_{p}$ denotes the specific heat capacity of the magnetic fluids given by
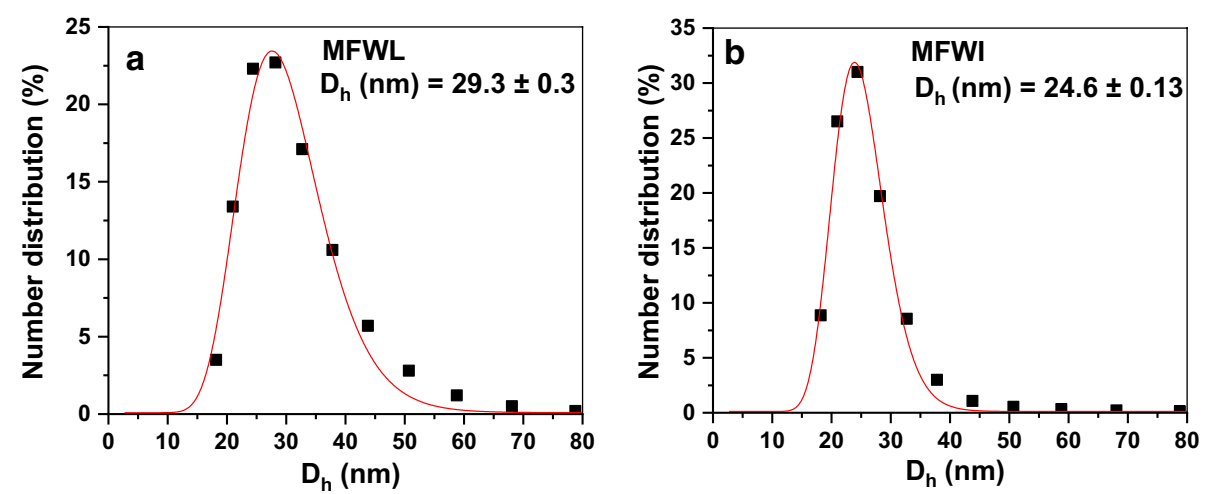

Fig. 5 DLS curve showing the number distribution of particles as a function of hydrodynamic size for aqueous a MFWL $\mathbf{b}$ MFWI. The line shows log-normal distribution fit to data 


$$
C_{p}=m_{\text {particles }} * C_{p-\text { particles }}+m_{\text {carrier }} * C_{p-\text { carrier }},
$$

where $\frac{\Delta T}{\Delta t}$ denotes the slope of the graph between temperature rise and induction heating time. $\phi_{\text {magnetic }}$ is the weight fraction of the magnetic content of particles. $C_{p}$ for carrier and particles was taken as 4.187 and $0.67 \mathrm{~J} / \mathrm{g}-\mathrm{K}$, respectively. For compensating the errors in measurement of SAR for non-adiabatic system, hyperthermia data were fitted with Box-Lucas Eq. 7 Kallumadil et al. 2009) given as follows:

$$
T(t)=A\left(1-e^{-B t}\right)
$$

where the rise in temperature, $T$ with respect to time, $t$ is given as a function of saturation temperature, $A$, and curvature of the heating curve, $B$. The product $A \times \mathrm{B}$ is equivalent to the initial heat rise rate, $\frac{\Delta T}{\Delta t}$, used in the SAR formula.

Figure $6 \mathrm{a}$ and $\mathrm{b}$ showd the temperature rise versus time and corresponding SAR values for MFWL diluted in the water, while Fig. $6 \mathrm{c}$ and $\mathrm{d}$ shows the same results for the MFWI sample. The experiments were repeated three times to check the reproducibility of results, and the variation in data is shown as error bar in the graphs. These fluids were diluted in deionized water to $10 \mathrm{mg} / \mathrm{mL}$ concentration, and the magnetic field was varied from 1.7 to $10 \mathrm{kA} / \mathrm{m}$. The rise in temperature, as well as corresponding SAR, was found to be higher for the larger magnetic field for both the fluids, as evident from the relation between SAR and magnetic field. This increase was greater for MFWL as compared to MFWI, indicating a better hyperthermic response of MFWL. This might be due to the slightly larger magnetic size of MNPs of MFWL compared to those of MFWI as heating would be more for large particle size due to Brownian relaxation. The increasing SAR with increasing particle size has been reported in the literature for $\gamma-\mathrm{Fe}_{2} \mathrm{O}_{3}$ nanoparticles (Purushotham et al. 2009) and $\mathrm{Fe}_{3} \mathrm{O}_{4}$ nanoparticles (Parekh et al. 2018). This is due to the fact that larger magnetic size will have a better response towards magnetic field direction as compared to the smaller size particles because the magnetic moment of particle is a function of particle size,

especially when it is in the nanometer range. Thus, the SAR shows variation with particle size.

In addition to this, it has also been reported (Rosensweig 2002) that the SAR should be dominated by the Brownian relaxation mechanism as compared to the Neel relaxation mechanism. The size distribution curve obtained from magnetic measurement for MFWL and MFWI samples (Inset Fig. 2b) indicated that almost $60 \%$ particles in MFWL sample is above the critical size of $9.2 \mathrm{~nm}$, whereas in the case of MFWI, it is $42 \%$. Larger the number of particles dominated by the Brownian relaxation mechanism more the induction heating response. Hence, the observed higher SAR value for MFWL as compared to MFWI is contended.

Figure $7 \mathrm{a}$ and $\mathrm{b}$ shows the temperature rise versus time and corresponding SAR values for MFWL diluted in the water while varying magnetic particle concentration. Figure $7 \mathrm{c}$ and $d$ shows the same for the MFWI sample. The magnetic field was kept fixed at 10 $\mathrm{kA} / \mathrm{m}$ for both the fluids and for all dilutions. From this figure, it is clear that the initial rise in temperature is faster as concentration increases, but when we calculated SAR, which takes care of particle concentration by normalizing the value of heating rate with particle concentration (as mentioned in Eq. 5), the value remained same. This indicates 

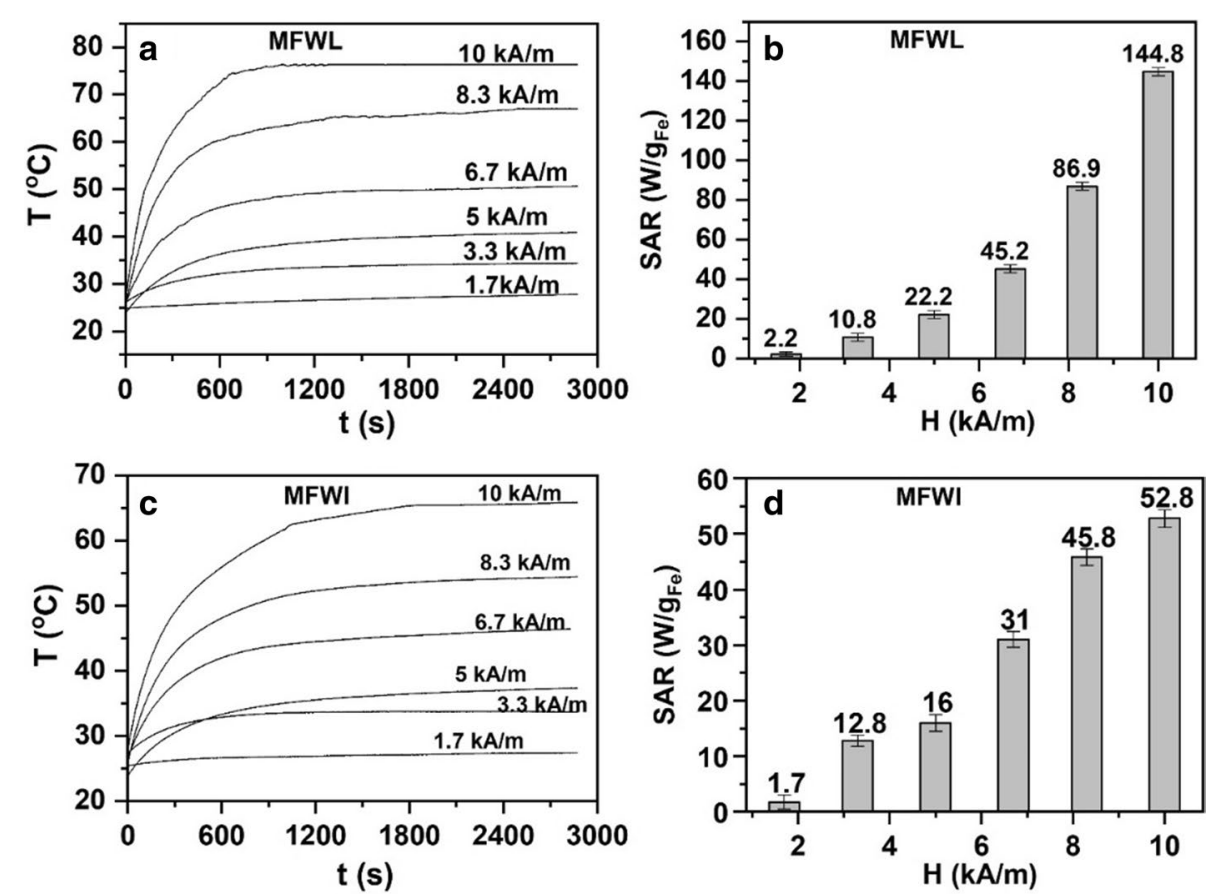

Fig. 6 Temperature versus time for different magnetic fields for a MFWL and c MFWI. Variation of SAR with magnetic field for $\mathbf{b}$ MFWL and $\mathbf{d}$ MFWI

that SAR is independent of concentration. Usually, the SAR is a function of magnetic field, frequency, particle composition, its size, shape, concentration, etc. When all other parameters are fixed except the particle concentration, then there is a possibility that with increasing or decreasing concentration, the particle-particle interaction or particle-carrier interaction play its role in creating the aggregation of the particles. In both cases, the SAR will be a function of particle concentration. Under such a situation, the system becomes more complex and non-predictable. Moreover, both conditions led to aggregation mechanism, which becomes more toxic to the cells. When SAR is independent of particle concentration, that means that the system is very stable upon dilution, and in order to increase the heating temperature, one can increase only the magnetic field strength. This is a very important inference; otherwise, it will be difficult to fix the concentration and magnetic field for induction heating experiments for in vitro cell line experiments. In the case of MFWI, the small variation in SAR with concentration may be due to the possibility of the formation of small aggregates. The possible reason for this may be the disturbance of charge layers around the particle surface because the dilution of magnetic fluids was carried out using distilled water having neutral $\mathrm{pH}$. However, this increase is within an error bar. Moreover, the induction heating is also performed only on the water (without dispersing MNPs) substantiated that heating was due to the MNPs and not because of radiative heating via the high current flowing through the coil. As reflected in Fig. 7a and c, the temperatures rise in water was less than $1{ }^{\circ} \mathrm{C}$ even after prolonged heating of the coil.

These experiments, related to hyperthermic response, with the variation of magnetic field and concentration, help to decide the concentration of magnetic fluids for in vitro 

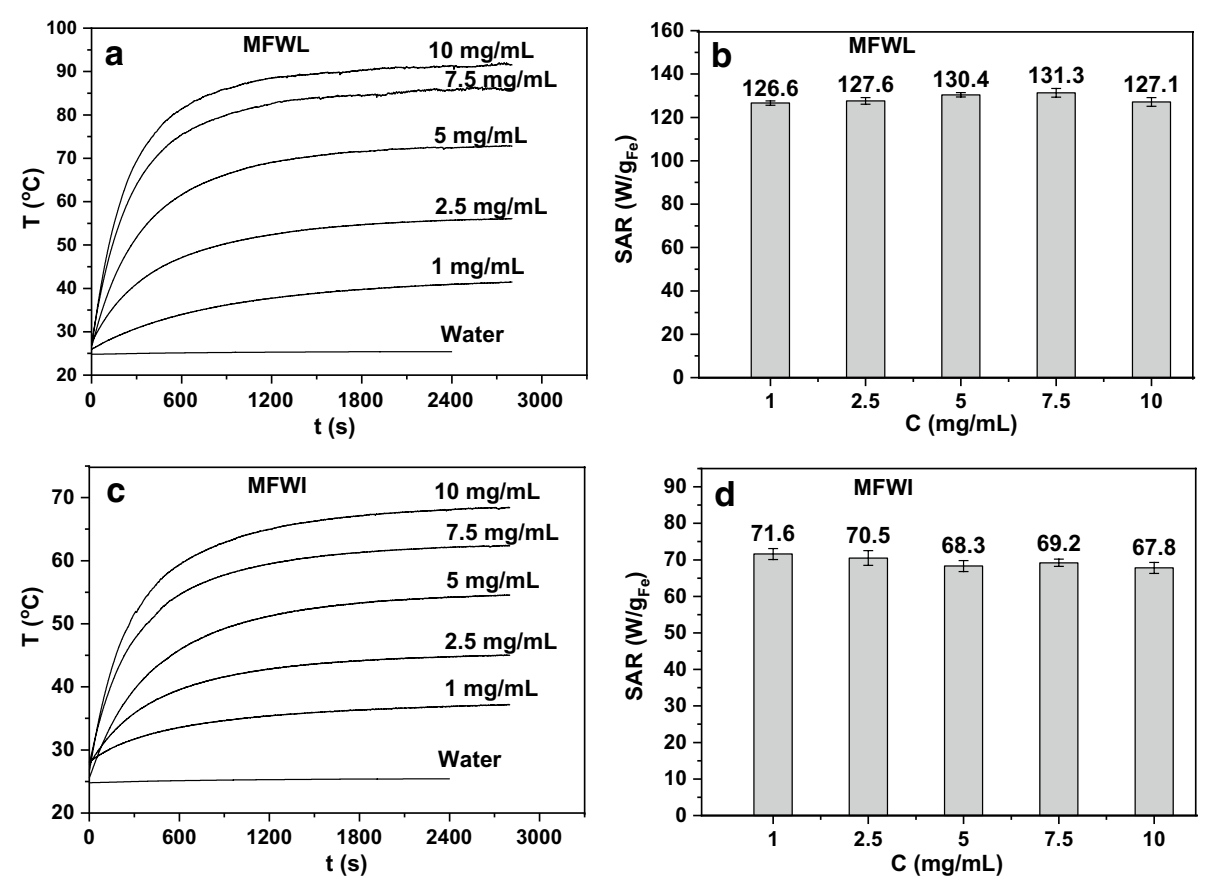

Fig. 7 Temperature versus time for different concentrations for a MFWL and c MFWI. Variation of SAR with concentrations for $\mathbf{b}$ MFWL and $\mathbf{d}$ MFWI

experiments and develop future magnetic fluid hyperthermia based in vivo therapeutic strategies on cancer patients. Overall, the experiments aimed to synthesize magnetic fluids with greater hyperthermic response at the lowest possible magnetic field and concentration at a given frequency.

\section{In vitro experiments}

To study the cytotoxic effect of the magnetic fluids, MTT assay was performed, and $\mathrm{IC}_{50}$ value was obtained. This assay provides a half-maximal inhibitory concentration, i.e., the $\mathrm{IC}_{50}$ value of the test compound required for $50 \%$ inhibition of viable cell numbers in vitro. The effect of different concentrations of MFWL and MFWI on cell viability via MTT assay is shown in Fig. $8 \mathrm{a}$ and b, respectively. Further, fitting Hill's equation to the dose-response curve (Hill 1910; Sebaugh 2011), the assay revealed $\mathrm{IC}_{50}$ values of $0.271 \mathrm{mg} / \mathrm{mL}$ and $0.206 \mathrm{mg} / \mathrm{mL}$ for MFWL and MFWI, respectively. A similar cytotoxicity study of lauric acid-coated magnetite particles on murine microglial BV2 cells was performed by Calatayud et al. (2017), who reported approximate $30 \%$ cell death after $24 \mathrm{~h}$ incubation with MNPs at a concentration of $0.1 \mathrm{mg} / \mathrm{mL}$ by performing TPB assay. However, using polyacrylic acid-coated MNPs under a similar experimental scenario, the same group observed almost 100\% viability of BV2 cells. Intriguingly, using the lauric acid-coated particles, Pradhan et al. (2007b) did not find any detrimental effect on human cervical cancer cells HeLa and mouse fibroblasts $\mathrm{L} 929$ at $0.1 \mathrm{mg} / \mathrm{mL}$ concentration; however, they observed approximate $8 \%$ cell death at $0.2 \mathrm{mg} / \mathrm{mL}$ concentration using sulforhodamine $\mathrm{B}$ assay. The $\mathrm{IC}_{50}$ of MFWL in the present study is in good agreement with the results of Freitas et al. (Freitas et al. 2008), who reported 50\% cell 

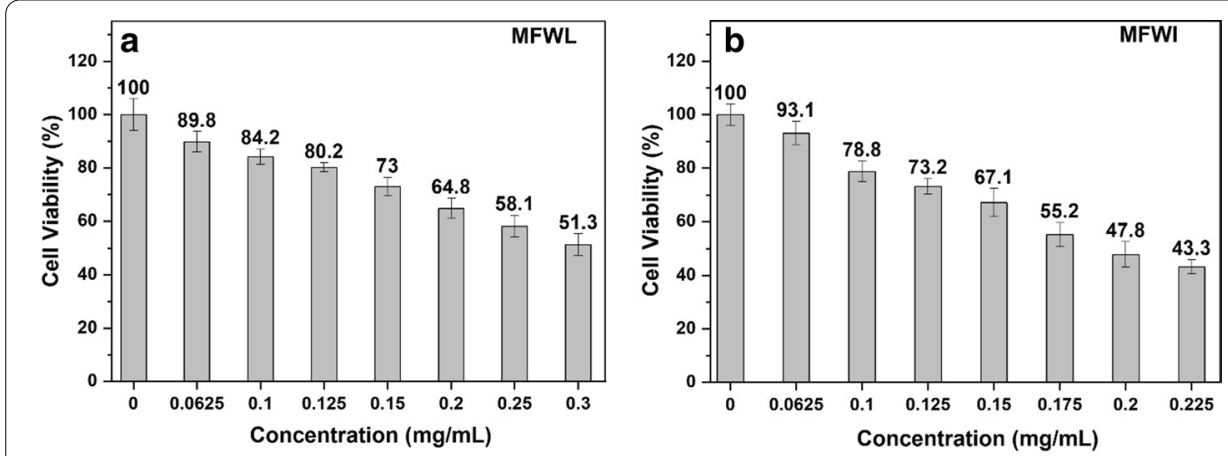

Fig. 8 Effect of different concentrations of $\mathbf{a}$ MFWL and $\mathbf{b}$ MFWI on cell viability using MTT assay

inhibition at $0.254 \mathrm{mg} / \mathrm{mL}$ using lauric acid-coated $\gamma-\mathrm{Fe}_{2} \mathrm{O}_{3}$ on human melanoma cells via MTT assay. The variation in the cell death percentage may be attributed to the difference in methods of MNPs synthesis, lauric acid coating, cells' physiologic features, types of cell lines used, as well as cell viability assay utilised. With regard to MFWI fluid, till date no report is available on its in vitro cytotoxic effect. However, a single in vivo study revealed toxic effect of ionic $\mathrm{MnFe}_{2} \mathrm{O}_{4}$ MF causing macrophage apoptosis, lymphocytes' DNA damage, and severe inflammatory response in the peritoneal cavity of mice (Lacava et al. 1999).

Our experiments related to induction heating on the water revealed that the heat generated was due to MNPs, and it was not radiative heating (Fig. 7a and c). Therefore, we proceeded to evaluate the effect of induction heating hyperthermia on HeLa cells at $15.3 \mathrm{kA} / \mathrm{m}$ and $330 \mathrm{kHz}$ after choosing the near $\mathrm{IC}_{50}$ values of 0.25 and $0.2 \mathrm{mg} / \mathrm{mL}$ for MFWL and MFWI, respectively. Looking at the concentration-dependent heating response from Fig. $7 \mathrm{a}$ and c, it is seen that more than $1 \mathrm{mg} / \mathrm{mL}$ concentration is required in both the samples to achieve the hyperthermia temperature of $45^{\circ} \mathrm{C}$. However, the $\mathrm{IC}_{50}$ value is very less than this concentration. The magnetic field used for this experiment was $10 \mathrm{kA} / \mathrm{m}$. Since the cell line experiments were carried out with the cell culture media, the $\mathrm{IC}_{50}$ dilution was also prepared in cell culture media for induction heating experiment. Additionally, as it is inferred from the above measurements that magnetic field strength can be used to increase the temperature, the heating response at $\mathrm{IC}_{50}$ concentration was investigated at $15.3 \mathrm{kA} / \mathrm{m}$ field.

Figure 9 shows the heating response for both the fluids as a function of time for $\mathrm{IC}_{50}$ concentration, 0.25 and $0.2 \mathrm{mg} / \mathrm{mL}$ for MFWL and MFWI, respectively, prepared in cell culture media and investigated at $15.3 \mathrm{kA} / \mathrm{m}$ field and $330 \mathrm{kHz}$ frequency. It is seen that $\mathrm{IC}_{50}$ dilution in cell culture media is able to achieve the heating temperature of $45^{\circ} \mathrm{C}$. The possible reason to achieve the required temperature even with the lower MNPs concentration can be due to the presence of ions and proteins in the cell culture media, which also takes part in the heating mechanism and contribute to the induction heating. Such type of study is also reported by Chanteau et al. (2009).

Although MTT assay is based on the metabolic response of cells and being less laborious and quick to perform to study cell death, TPB assay was performed for hyperthermic study to have an absolute visualization of the cell death under a microscope. Live and dead cells were observed under the microscope, and the viability of 
cells was calculated using the ratio of live cells to the total (live + dead) cells which was normalized against the control cells.

Figure 10a and $\mathrm{b}$ shows the cell viabilities obtained after MFH utilizing MFWL and MFWI, respectively. Reduction in cell count, as well as morphologic alteration observed after MFH by MFWL and MFWI, are represented in Fig. 10c1 to c4 and d1 to d4, respectively. Due to hyperthermia alone, i.e., without MF, after 30- and 60-min' sessions, cell death was approximately 7 and 15\%, respectively. Cells under magnetic filed usually show cell death up to $5 \%$ that may be due to mechanical stress faced by cells as a part of experimental procedures. However, under alternating magnetic field, approximately $85 \%$ of cells showed viability even when the induction heating time was increased to $60 \mathrm{~min}$. This suggests that the cells well endured the magnetic field and heat-shock without major population loss. It would also be interesting to analyze the expression of heat-shock proteins such as HSP27/HSP70 and HSP90 as these proteins are known to overexpress in cancer under the hyperthermic condition and provides resistance to damage caused by temperature rise, thereby the therapeutic efficacy of chemotherapy (Grimmig et al. 2017). In addition, another reason for cell death under the influence of magnetic field could be the generation of reactive oxygen species in the cells as reviewed by Wang and Zhang (2017).

Considering MFWL, $24 \mathrm{~h}$ treatment without hyperthermia resulted in an approximate 38\% cell death, whereas MFWI caused around 55\% cell death. Further, MFWL, after $24 \mathrm{~h}$ of MF treatment and subsequent $30 \mathrm{~min}$ HT led to about $45 \%$ cell death that was augmented to around $68 \%$ after $24 \mathrm{~h} \mathrm{MF}$ treatment and 60 min HT session. On the other hand, MFWI was comparatively toxic than MFWL that resulted in an approximate $68 \%$ and $80 \%$ cell death under the same hyperthermic experimental conditions. All the groups in both fluids showed significant cell death compared to control groups $(p<0.05 ; p<0.01)$. This high rate of cell death due to MNPs without induction heating might have occurred due to MNPs aggregation in the media (Eberbeck et al. 2010), leading to a change in MNP concentration. Another reason could be the toxicity exhibited by the surfactant (Pradhan et al. 2007b). Furthermore, a higher rate of cell death observed

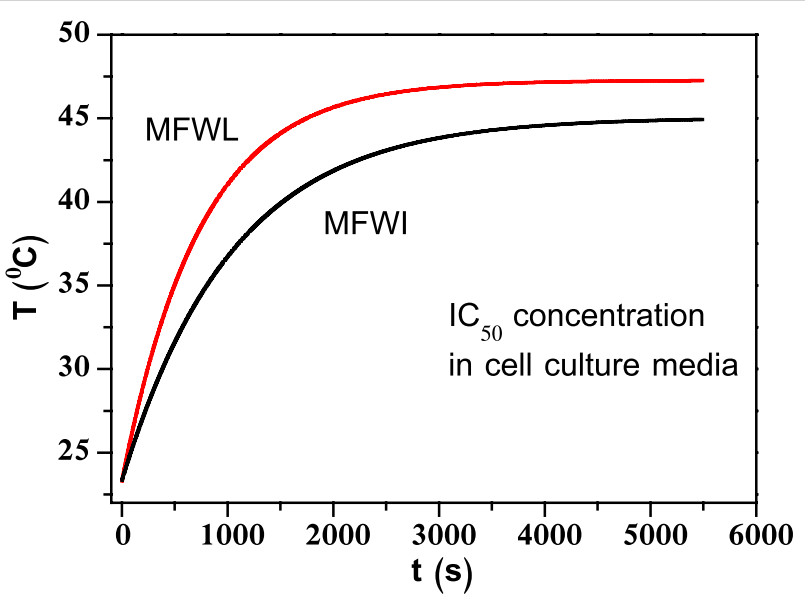

Fig. 9 Temperature versus time for $0.25 \mathrm{mg} / \mathrm{mL}$ concentration of MFWL and $0.2 \mathrm{mg} / \mathrm{mL}$ concentration of MFWI sample in cell culture media at $15.3 \mathrm{kA} / \mathrm{m}$ and $330 \mathrm{kHz}$ 

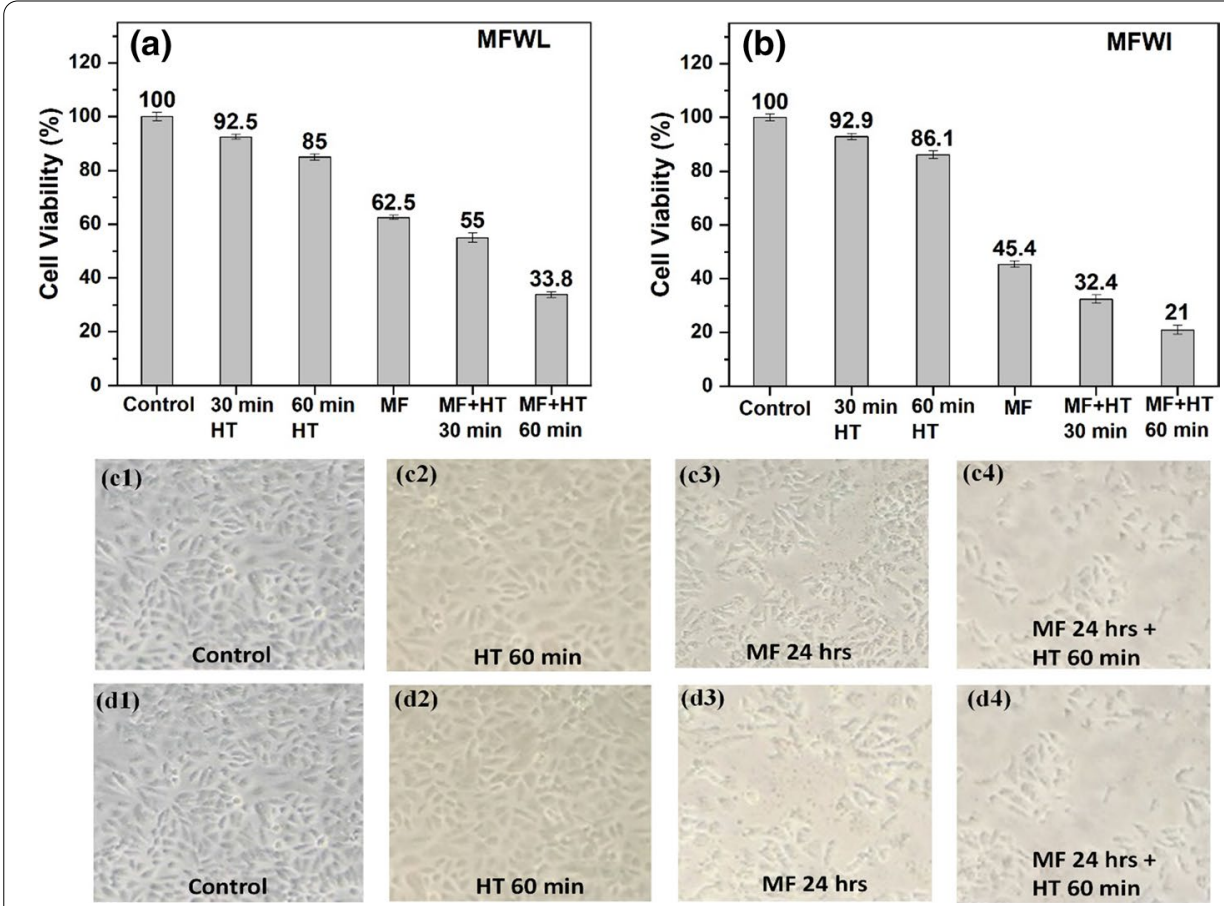

Fig. 10 Hyperthermic effect of a MFWL and $\mathbf{b}$ (MFWI) on HeLa cells' viability using TPB assay. Microscopic images of the control cells without MF and without HT (c1 and d 1); after 60 min hyperthermia without MFWL (c2) and without MFWI (d2); after $24 \mathrm{~h}$ interaction with MFWL (c3), and MFWI (d3); and after $24 \mathrm{~h}$ interaction and 60 min hyperthermia with MFWL (c4) and MFWI (d4)

due to charged MF as compared to lauric acid-coated MF can be attributed to a change in membrane potential due to the presence of charge on the MNPs leading to disruption of cells' plasma membrane, thereby inducing cell death. Membrane potential studies are warranted to understand the mechanism of cell death caused by charged magnetic fluids.

With regard to the effect of surfactant on MFH, our results corroborate with the findings of Calatayud et al. (2017) who observed an approximate $44 \%$ cell death using polyacrylic acid-coated iron oxide MNPs on microglial BV2 cells after 30 min of hyperthermia, however, at a higher frequency $560 \mathrm{kHz}$ and field $23.9 \mathrm{kA} / \mathrm{m}$. Similarly, Hedayatnasab et al. (2020), reported 40 and $60 \%$ cell death at $31.47 \mathrm{kA} / \mathrm{m}$ and $47.24 \mathrm{kA} / \mathrm{m}$ fields, respectively, using polycaprolactone (PCL) coated cetyl trimethyl ammonium bromide (CTAB)-modified iron oxide particles on human liver carcinoma cells HepG2 at a concentration of $0.1 \mathrm{mg} / \mathrm{mL}$, while maintaining the hyperthermic window of 43 to $46{ }^{\circ} \mathrm{C}$. Interestingly, they incubated the cells with MNPs only for 4 hours before MFH compared to $24 \mathrm{~h}$ incubation of ours. Previously we reported the effect of MFH on HeLa cells using lauric acid-coated $\mathrm{Mn}-\mathrm{Zn}$ ferrite fluid under the same frequency and field that resulted in 55 and $60 \%$ cell death after 30 and 60 min treatment, respectively, at $0.35 \mathrm{mg} / \mathrm{mL}$ concentration (Bhardwaj et al. 2020). Enhanced cell death of 70 and $76 \%$ after 30 and $60 \mathrm{~min}$ of treatment, respectively, was observed when hyperthermia was performed using MF of $0.75 \mathrm{mg} / \mathrm{mL}$ concentration (Parekh et al. 2020). Comparing the hyperthermic effect of different MF types on cell viability in the present study and our 
previous reports, the MFWI was found to be more toxic at a lower concentration, followed by MFWL. One of the limitations of our study was the observed cytotoxicity due to MF alone without induction heating. MFs leading to effective killing of cancer cells after induction heating are desirable. Overall, our study results suggest that the outer stabilizing layer, MF concentration, and hyperthermia duration are essential parameters for designing and planning future MFH based therapy against cancer.

\section{Conclusions}

The present study reports cytotoxicity of magnetic fluids on HeLa cells stabilized using two different approaches: (i) sterically stabilized fluid and (ii) ionic stabilized fluid. The crystallite size of surfactant-stabilized particles (MFWL) was higher $(11.0 \pm 0.5 \mathrm{~nm})$ compared to the charge stabilized particles $(8.3 \pm 0.5 \mathrm{~nm})$. The magnetic size was measured to be $10.3 \mathrm{~nm}$ and $8.2 \mathrm{~nm}$, respectively, for surfacted and ionic magnetic fluid. The hydrodynamic size obtained was $29.3 \pm 0.3 \mathrm{~nm}$ and $24.6 \pm 0.3 \mathrm{~nm}$, respectively, for MFWL and MFWI. The observed hydrodynamic size was higher as compared to the crystallite size due to the consideration of the layer of surfactant as well as dispersion medium around the particles. Both TGA and FTIR results revealed chemically bound layer of surfactant or charge around the particle surface. Induction heating experiments showed that the SAR of the surfactant-coated particles was almost double compared to ionic particles, possibly due to the reduced size of MFWI compared to MFWL. SAR of MF was analyzed at different magnetic field strengths and varying concentration of magnetic particles using induction heating applicator at $330 \mathrm{kHz}$ frequency. The cytotoxicity of the optimized concentration of magnetic fluids was examined on HeLa cells by performing MTT and TPB assays. A maximum 1-hour induction heating using the surfactant-coated magnetic fluid led to an approximately $66 \%$ cell death at the concentration of $0.25 \mathrm{mg} / \mathrm{mL}$, whereas charged magnetic fluid caused a cell death up to $80 \%$ at $0.2 \mathrm{mg} / \mathrm{mL}$ concentration. The preliminary analysis of this study shows significant cell death due to hyperthermia, wherein MFWI revealed higher cytotoxicity compared to MFWL. Further investigations into the role of MNPs'outer stabilizing layer, MF amount, and hyperthermic duration are desirable to utilized MFH as a futuristic anti-cancer therapeutic approach.

\footnotetext{
Abbreviations

MFH: Magnetic fluid hyperthermia; MNPs: Magnetic nanoparticles; MFWL: Surfactant-coated magnetic fluid; MFWI: Ionic magnetic fluid; XRD: X-ray diffraction; VSM: Vibrating sample magnetometer; DLS: Dynamic light scattering; TGA :Thermogravimetric analyzer; FTIR: Fourier transform infrared spectrometer; SAR: Specific absorption rate; PEG: Polyethylene glycol; PVA: Polyvinyl alcohol; PVP: Polyvinyl pyrrolidine; EMEM: Eagle's minimal essential medium; MTT assay: 3-(4, 5-Dimethylthiazol-2-yl)-2, 5-diphenyltetrazolium bromide; PBS: Phosphate-buffered saline; ELISA: Enzyme linked immunoassay; CDs: Culture dishes; TPB assays: Trypan blue assay; HT: Hyperthermia.
}

\section{Acknowledgements}

Authors acknowledges the Science and Engineering Research Board (SERB), Department of Science \& Technology (DST), Government of India, New Delhi for providing financial support to carry out the work under the Extra Mural Research (EMR) scheme vide ref. No. SERB/EMR/2016/001000.

\section{Authors' contributions}

$A B$ performed synthesis and characterization of the magnetic fluid and performed cell culture experiments. KP and NJ designed the experimental protocols and results analysis of the samples. AB, NJ and KP contributed to writing the manuscript. All authors reviewed the final draft of the manuscript. All authors read and approved the final manuscript.

\section{Funding}

The work was carried out under the Extra Mural Research (EMR) scheme vide ref. No. SERB/EMR/2016/001000 of Science and Engineering Research Board (SERB), Department of Science \& Technology (DST), Government of India, New Delhi. 
Availability of data and materials

The data will be available if needed.

\section{Ethics approval and consent to participate}

Not Applicable.

\section{Consent for publication}

All authors agrees with the publication of this manuscript in this journal.

\section{Competing interests}

The authors declare that there is no conflict of interest.

Received: 1 December 2020 Accepted: 16 January 2021

Published online: 08 February 2021

\section{References}

Bhardwaj A, Parekh K, Jain N. In vitro hyperthermic effect of magnetic fluid on cervical and breast cancer cells. Sci Rep. 2020;10(1):15249. https://doi.org/10.1038/s41598-020-71552-3.

Calatayud MP, Soler E, Torres TE, Campos-Gonzalez E, Junquera C, Ibarra MR, Goya GF. Cell damage produced by magnetic fluid hyperthermia on microglial BV2 cells. Sci Rep. 2017;7(1):8627. https://doi.org/10.1038/s41598-017-09059-7.

Cao G, Wang Y. Nanostructures \& nanomaterials: synthesis, properties, and applications. 2nd ed. New Jersey: World Scientific; 2011.

Chang D, Lim M, Goos JACM, Qiao R, Ng YY, Mansfeld FM, Jackson M, Davis TP, Kavallaris M. Biologically targeted magnetic hyperthermia: potential and limitations. Front Pharmacol. 2018;9:831. https://doi.org/10.3389/fphar.2018.00831.

Chanteau B, Fresnais J, Berret J-F. Electrosteric enhanced stability of functional sub-10 $\mathrm{nm}$ cerium and iron oxide particles in cell culture medium. Langmuir. 2009;25(16):9064-70. https://doi.org/10.1021/la900833v.

Das P, Colombo M, Prosperi D. Recent advances in magnetic fluid hyperthermia for cancer therapy. Colloids Surf B. 2019;174:42-55. https://doi.org/10.1016/j.colsurfb.2018.10.051.

de Freitas ERL, Soares PRO, de Paula Santos R, dos Santos RL, da Silva JR, Porfirio EP, Báo SN, de Oliveira Lima EC, Morais PC Guillo LA (2008) In Vitro Biological Activities of Anionic y -Fe 2 O 3 Nanoparticles on Human Melanoma Cells.j nanosci nanotechnol 8(5):2385-2391. doi:https://doi.org/10.1166/jnn.2008.275.

Eberbeck D, Kettering M, Bergemann C, Zirpel P, Hilger I, Trahms L. Quantification of the aggregation of magnetic nanoparticles with different polymeric coatings in cell culture medium. J Phys D: Appl Phys. 2010;43(40):405002. https://doi. org/10.1088/0022-3727/43/40/405002.

Filippousi M, Angelakeris M, Katsikini M, Paloura E, Efthimiopoulos I, Wang Y, Zamboulis D, Van Tendeloo G. Surfactant effects on the structural and magnetic properties of iron oxide nanoparticles. J Phys Chem C. 2014;118(29):16209-17. https:// doi.org/10.1021/jp5037266.

Giri J, Pradhan P, Somani V, Chelawat H, Chhatre S, Banerjee R, Bahadur D. Synthesis and characterizations of water-based ferrofluids of substituted ferrites [Fe1 $-x B \times F e 2 \mathrm{O} 4, \mathrm{~B}=\mathrm{Mn}, \mathrm{Co}(\mathrm{x}=0-1)]$ for biomedical applications. J Magn Magn Mater. 2008:320(5):724-30. https://doi.org/10.1016/j.jmmm.2007.08.010.

Grimmig T, Moll E-M, Kloos K, Thumm R, Moench R, Callies S, Kreckel J, Vetterlein M, Pelz J, Polat B, Tripathi S, Rehder R, Ribas CM, Chandraker A, Germer C-T, Waaga-Gasser AM, Gasser M. Upregulated heat shock proteins after hyperthermic chemotherapy point to induced cell survival mechanisms in affected tumor cells from peritoneal carcinomatosis. Cancer Growth Metastasis. 2017:10:117906441773055. https://doi.org/10.1177/1179064417730559.

Hedayatnasab Z, Dabbagh A, Abnisa F, Wan Daud WMA. Polycaprolactone-coated superparamagnetic iron oxide nanoparticles for in vitro magnetic hyperthermia therapy of cancer. Eur Polymer J. 2020;133:109789. https://doi.org/10.1016/j. eurpolymj.2020.109789.

Hill A. The possible effects of the aggregation of the molecules of haemoglobin on its dissociation curves. J Physiol. 1910;40:4-7

Hondow N, Brydson R, Wang P, Holton MD, Brown MR, Rees P, Summers HD, Brown A. Quantitative characterization of nanoparticle agglomeration within biological media. J Nanopart Res. 2012;14(7):977. https://doi.org/10.1007/s1 105 1-012-0977-3.

Kallumadil M, Tada M, Nakagawa T, Abe M, Southern P, Pankhurst QA. Suitability of commercial colloids for magnetic hyperthermia. J Magn Magn Mater. 2009;321(10):1509-13. https://doi.org/10.1016/j.jmmm.2009.02.075.

Khalafalla SE, Reimers GW, Rholl SS. Dilution stable water based magnetic fluids. 1980. US Patent US4, 208, 294, 17 Jun 1980.

Lacava ZGM, Azevedo RB, Martins EV, Lacava LM, Freitas MLL, Garcia VAP, Rébula CA, Lemos APC, Sousa MH, Tourinho FA, Da Silva MF, Morais PC. Biological effects of magnetic fluids: toxicity studies. J Magn Magn Mater. 1999;201(1-3):431-4. https ://doi.org/10.1016/S0304-8853(99)00002-5.

Laffon B, Fernández-Bertólez N, Costa C, Brandão F, Teixeira JP, Pásaro E, Valdiglesias V. Cellular and molecular toxicity of iron oxide nanoparticles. In: Saquib Q, Faisal M, Al-Khedhairy AA, Alatar AA, editors. Cellular and molecular toxicology of nanoparticles. Cham: Springer International Publishing; 2018. p. 199-213.

Lenin $\mathrm{R}$, Joy PA. Role of primary and secondary surfactant layers on the thermal conductivity of lauric acid coated magnetite nanofluids. J Phys Chem C. 2016;120(21):11640-51. https://doi.org/10.1021/acs.jpcc.5b12476.

Mahdavi M, Ahmad M, Haron M, Namvar F, Nadi B, Rahman M, Amin J. Synthesis, surface modification and characterisation of biocompatible magnetic iron oxide nanoparticles for biomedical applications. Molecules. 2013;18(7):7533-48. https:// doi.org/10.3390/molecules 18077533.

Massart R. Preparation of aqueous magnetic liquids in alkaline and acidic media. IEEE Trans Magn. 1981;17(2):1247-8. https:// doi.org/10.1109/TMAG.1981.1061188. 
Maxwell DJ, Bonde J, Hess DA, Hohm SA, Lahey R, Zhou P, Creer MH, Piwnica-Worms D, Nolta JA. Fluorophore-conjugated iron oxide nanoparticle labeling and analysis of engrafting human hematopoietic stem cells. Stem Cells. 2008;26(2):51724. https://doi.org/10.1634/stemcells.2007-0016.

Mosmann T. Rapid colorimetric assay for cellular growth and survival: application to proliferation and cytotoxicity assays. J Immunol Methods. 1983;65(1-2):55-63. https://doi.org/10.1016/0022-1759(83)90303-4.

Obaidat I, Issa B, Haik Y. Magnetic properties of magnetic nanoparticles for efficient hyperthermia. Nanomaterials. 2015;5(1):63-89. https://doi.org/10.3390/nano5010063.

Odenbach S, editor. Ferrofluids: magnetically controllable fluids and their applications. New York: Springer, Berlin; 2002.

Parekh K, Upadhyay RV. The effect of magnetic field induced aggregates on ultrasound propagation in aqueous magnetic fluid. J Magn Magn Mater. 2017;431:74-8. https://doi.org/10.1016/j.jmmm.2016.08.024.

Parekh K, Upadhyay RV, Mehta RV, Aswal VK. Experimental investigation of nearly monodispersed ternary Mn0.5Zn0.5Fe2O4 magnetic fluid. MHD. 2008;44(1):19-26. https://doi.org/10.22364/mhd.44.1.3.

Parekh K, Parmar H, Sharma V, Ramanujan RV. Heating efficiency dependency on size and morphology of magnetite nanoparticles. In: AIP Conference Proceedings. American Institute of Physics Inc., 2018. p 050022.

Parekh K, Bhardwaj A, Jain N. Preliminary in-vitro investigation of magnetic fluid hyperthermia in cervical cancer cells. J Magn Magn Mater. 2020;497:166057. https://doi.org/10.1016/j.jmmm.2019.166057.

Patil U, Adireddy S, Jaiswal A, Mandava S, Lee B, Chrisey D. In Vitro/in vivo toxicity evaluation and quantification of iron oxide nanoparticles. IJMS. 2015;16(10):24417-50. https://doi.org/10.3390/ijms161024417.

Patterson AL. The scherrer formula for X-Ray Particle size determination. Phys Rev. 1939;56(10):978-82. https://doi. org/10.1103/PhysRev.56.978.

Pradhan P, Giri J, Samanta G, Sarma HD, Mishra KP, Bellare J, Banerjee R, Bahadur D. Comparative evaluation of heating ability and biocompatibility of different ferrite-based magnetic fluids for hyperthermia application. J Biomed Mater Res. 2007a;81B(1):12-22. https://doi.org/10.1002/jbm.b.30630

Pradhan P, Giri J, Banerjee R, Bellare J, Bahadur D. Cellular interactions of lauric acid and dextran-coated magnetite nanoparticles. J Magn Magn Mater. 2007b;311(1):282-7. https://doi.org/10.1016/j.jmmm.2006.10.1181.

Purushotham S, Chang PEJ, Rumpel H, et al. Thermoresponsive core-shell magnetic nanoparticles for combined modalities of cancer therapy. Nanotechnology. 2009. https://doi.org/10.1088/0957-4484/20/30/305101.

Rosensweig RE. Heating magnetic fluid with alternating magnetic field. J Magn Magn Mater. 2002;252:370-4. https://doi. org/10.1016/S0304-8853(02)00706-0.

Sebaugh JL. Guidelines for accurate EC50/IC50 estimation. Pharmaceut Statist. 2011;10(2):128-34. https://doi.org/10.1002/ pst.426.

Soares PIP, Alves AMR, Pereira LCJ, Coutinho JT, Ferreira IMM, Novo CMM, Borges JPMR. Effects of surfactants on the magnetic properties of iron oxide colloids. J Colloid Interface Sci. 2014;419:46-51. https://doi.org/10.1016/j.jcis.2013.12.045.

Strober W. Trypan blue exclusion test of cell viability. Curr Protoc Immunol Appendix. 2001. https://doi.org/10.1002/04711 42735.ima03bs21.

Su C-H, Tsai C-Y, Tomanek B, Chen W-Y, Cheng F-Y. Evaluation of blood-brain barrier-stealth nanocomposites for in situ glioblastoma theranostics applications. Nanoscale. 2016;8(15):7866-70. https://doi.org/10.1039/C6NR00280C.

Suryanarayana C, Norton MG. X-Ray diffraction: a practical approach. New York: Plenum Press; 1998.

Tourinho FA, Franck R, Massart R. Aqueous ferrofluids based on manganese and cobalt ferrites. J Mater Sci. 1990;25(7):324954. https://doi.org/10.1007/BF00587682.

Wang H, Zhang X. Magnetic fields and reactive oxygen species. IJMS. 2017;18(10):2175. https://doi.org/10.3390/ijms181021 75.

Wu W, He Q, Jiang C. Magnetic iron oxide nanoparticles: synthesis and surface functionalization strategies. Nanoscale Res Lett. 2008:3(11):397-415. https://doi.org/10.1007/s11671-008-9174-9.

Xu JK, Zhang FF, Sun JJ, et al. Bio and nanomaterials based on Fe3O4. Molecules. 2014;19:21506-28.

Zavisova V, Koneracka M, Gabelova A, et al. Effect of magnetic nanoparticles coating on cell proliferation and uptake. J Magn Magn Mater. 2019;472:66-73. https://doi.org/10.1016/j.jmmm.2018.09.116.

\section{Publisher's Note}

Springer Nature remains neutral with regard to jurisdictional claims in published maps and institutional affiliations. 